\title{
ANALISIS TRAGEDI SEMANGGI I TERHADAP UPAYA PENUNTUTAN PENYELESAIAN PELANGGARAN HAM
}

\author{
Annisa Azzahra \\ Program Pendidikan Vokasi Universitas Brawijaya \\ aazzahra658@gmail.com
}

\begin{abstract}
Abstrak
Tulisan ini bertujuan untuk menganalisis sejauhmana upaya penuntutan penyelesaian pelanggaran HAM pada tragedi Semanggi I tanggal 11-13 November 1998. Melalui penelusuran pustaka dan media massa, diuraikan dengan membuat acara bertajuk "Antologi: Pameran, Cerita, Memoribilia, dan Foto Tragedi Semanggi". Peristiwa ini menjadikan pembelajaran khususnya kepada mahasiswa yang menghendaki adanya perubahan sistem pemerintahan, terwujudnya pemerintahan yang demokratis, menginginkan adanya perubahan di dalam agenda perubahan reformasi. Kesadaran dan pemahaman terhadap Hak Asasi Manusia dan hukum harus terus ditingkatkan agar tercipta iklim yang damai, aman, serta nyaman di Indonesia. Pemerintah Jokowi-JK berkomitmen untuk menyelesaikan kasus-kasus terkait pelanggaran HAM di masa lalu termasuk Tragedi Semanggi I yang selama ini menjadi beban sosial masyarakat Indonesia. Langkah-langkah nyata telah dilakukan oleh pemerintah dalam mewujudkan komitmennya. Dengan demikian, upaya penuntutan penyelesaian pelanggaran HAM dari tragedi Semanggi I diharapkan segera tuntas, tidak hanya harapan kosong yang diberikan.
\end{abstract}

Kata kunci : Tragedi Semanggi I, Mahasiswa, Hak Asasi Manusia.

\begin{abstract}
This paper aims to analyze the extent of the efforts to prosecute the resolution of human rights violations in the Semanggi I tragedy on 11-13 November 1998. Through searching the literature and mass media, elaborated by making the event titled "Anthology: Exhibition, Story, Memoribilia, and Semanggi Tragedy Photo". This event makes learning especially for students who want a change in the government system, the realization of a democratic government, want a change in the reform reform agenda. Awareness and understanding of Human Rights and the law must continue to be improved in order to create a peaceful, safe and comfortable climate in Indonesia. The Jokowi-JK government is committed to resolving cases related to past human rights violations including the Semanggi I Tragedy which has been a social burden for the Indonesian people. Concrete steps have been taken by the government in realizing its commitment. Thus, efforts to prosecute the resolution of human rights violations from the Semanggi I tragedy are expected to be resolved soon, not just empty hopes given.
\end{abstract}

Keywords: Trisakti Tragedy, Students, Human Rights

Jurnal Academia Praja Volume 3 Nomor 1 - Februari 2020 


\section{PENDAHULUAN}

Dalam Undang-Undang Nomor 39 Tahun 1999 tentang Hak Asasi Manusia Pasal 1 disebutkan bahwa :

"Hak Asasi Manusia (HAM) adalah seperangkat hak yang melekat pada hakikat dan keberadaan manusia sebagai makhluk Tuhan Yang Maha Esa dan merupakan anugerah-Nya yang wajib dihormati, dijunjung tinggi, dan dilindungi oleh negara, hukum, pemerintah dan setiap orang demi kehormatan serta perlindungan harkat dan martabat manusia".

Hak asasi manusia memiliki beberapa ciri-ciri khusus jika dibandingkan dengan hak-hak lainnya. Berikut ini penjelasan mengenai ciri ciri HAM :

1. Tidak dapat dicabut, artinya hak asasi manusia tidak dapat dihilangkan atau diserahkan.

2. Tidak dapat dibagi, artinya semua orang berhak mendapatkan semua hak, apakah hak sipil dan politik atau hak ekonomi, social, dan budaya.

3. Hakiki, artinya hak asasi manusia adalah hak asasi semua umat manusia yang sudah ada sejak lahir.

4. Universal, artinya hak asasi manusia berlaku untuk semua orang tanpa memandang status, suku bangsa, gender, atau perbedaan lainnya. Persamaan adalah salah satu dari ide-ide hak asasi manusia yang mendasar.

Ada beberapa jenis dan macam hak asasi manusia, namun secara garis besar hak asasi manusia dapat digolongkan menjadi 6 macam, berikut ini macam macam HAM :

1. Hak Asasi Pribadi (Personal Rights), yaitu hak yang masih berhubungan dengan kehidupan pribadi manusia.

2. Hak Asasi Politik (Political Rights),yaitu hak yang berhubungan dengan kehidupan politik.

3. Hak Asasi Hukum (Legal Equality Rights), yaitu hak yang berhubungan dengan berbagai kehidupan hukum dan juga pemerintahan.

4. Hak Asasi Ekonomi (Property Rights), yaitu hak yang berhubungan dengan berbagai kegiatan perekonomian. 
5. Hak Asasi Sosial Budaya (Social Culture Rights), yaitu hak yang berhubungan dengan kehidupan dalam bermasyarakat

6. Hak Asasi Peradilan (Procedural Rights), yaitu hak untuk diperlakukan sama terhadap tata cara pengadilan.

Sedangkan menurut pasal 1 ayat (6) Undang-Undang Nomor 39 Tahun 1999 tentang HAM, yang dimaksud Pelanggaran Hak Asasi Manusia adalah :

"Setiap pelanggaran seseorang atau sekelompok orang termasuk aparat Negara baik disengaja maupun tidak disengaja atau kelalaian yang secara melawan hukum mengurangi, menghalangi, membetasi, dan atau mencabut hak asasi manusia seseorang atau kelompok orang yang dijamin oleh undang-undang ini, dan tidak mendapatkan, atau dikhawatirkan tidak akan memperoleh penyelesaian hukum yang adil dan benar, berdasarkan mekanisme hukum yang berlaku".

Salah satu janji kampanye JokowiJK yang tercantum dalam visi dan misi Nawacita adalah komitmen mereka untuk menyelesaikan kasus-kasus pelanggaran HAM dimasa lalu yang sampai saat ini masih menjadi beban sosial bangsa Indonesia. Komitmen tersebut dipertegas pada peringatan hari HAM di Istana Negara akhir tahun 2015, Presiden menyatakan bahwa kita semua harus mempunyai keberanian untuk melakukan rekonsiliasi atau mencari terobosan penyelesaian melalui jalur-jalur yudisial ataupun non yudisial. Kecuali itu JokowiJK juga berjanji akan memasukkan perlindungan HAM dalam Rencana Pembangunan Jangka Menengah (RPJM). Langkah nyata terkini yang dilakukan Presiden Jokowi adalah menemui 22 praktisi dan akademisi hukum dan menegaskan komitmennya untuk menyelesaikan kasus HAM di masa lalu.

Komitmen tersebut memperkuat argumen kalangan optimistis soal upaya sungguh-sungguh dari pemerintah untuk menyelesaikan kasus-kasus HAM yang belum terselesaikan di Indonesia. Kalangan optimistis juga yakin pemerintah tengah berupaya menomor satukan kembali perlindungan HAM yang selama ini dinomorduakan demi mengatasi masalah lambatnya perekonomian. Sementara itu kalangan skeptis meragukan komitmen tersebut karena Presiden Jokowi menyerahkan penyelesaian kasus HAM kepada pejabat-pejabat strategis sipil dan militer yang terkena kasus di masa lalu sehingga upaya ini akan berhenti ditengah jalan atau bahkan tidak akan pernah terselesaikan karena faktor kepentingan. 
Pelanggar-pelanggar HAM semestinya dilarang menduduki jabatan publik demi mencegah keberulangan yang dilakukan oleh mereka di masa lalu.

Ada beberapa peristiwa masa lalu yang belum terselesaikan hingga saat ini, terkait dengan pelanggaran HAM, salah satu diantaranya adalah Tragedi Semanggi I. Di Indonesia, pada 13 November 1998 terjadi peristiwa kerusuhan di kawasan Semanggi, Jakarta Selatan yang dilakukan oleh mahasiswa ketika menyuarakan protes terhadap pemerintahan Bacharuddin Jusuf Habibie. Pada tanggal 11 November 1998, mahasiswa dan masyarakat yang bergerak dari Jalan Salemba bentrok dengan Pamswakarsa di kompleks Tugu Proklamasi. 12 November 1998, ratusan ribu maasiswa dan masyarakat bergerak menuju gedung DPR/MPR dari segala arah, Semanggi-Slipi-Kuningan. Tetapi, tidak ada yang berhasil menembus ke sana karena dikawal dengan sangat ketat oleh TNI, Brimob, dan juga Pamswakarsa. Pada malam harinya, terjadi bentrok pertama kali di daerah Slipi dan puluhan mahasiswa masuk rumah sakit. Satu orang pelajar, yaitu Lukman Firdaus, terluka berat dan masuk rumah sakit. Beberapa hari kemudian ia meninggal dunia.

13 November 1998, banyak mahasiswa dan masyarakat sudah bergabung dan mencapai daerah Semanggi dan sekitarnya, bergabung dengan mahasiswa yang sudah ada di depan kampus Atma Jaya Jakarta. Jalan Sudirman sudah dihadang oleh aparat sejak malam hari dan pagi. Hingga siang harinya, jumlah aparat semakin banyak guna menghadang laju mahasiswa dan masyarakat. Mahasiswa dan masyarakat dikepung dari dua arah sepanjang Jalan Sudirman dengan menggunakan kendaraan lapis baja. Jumlah masyarakat dan mahasiswa yang bergabung diperkirakan puluhan ribu orang. Sekitar jam 15.00 WIB, kendaraan lapis baja mulai bergerak untuk membubarkan massa, membuat masyarakat melarikan diri, lalu dipapar tembakan membabi buta oleh aparat. Saat itu, sudah ada mahasiswa yang tertembak dan tewas di jalan bernama Teddy Wardhani Kusuma.

Mahasiswa terpaksa lari ke kampus Atma Jaya untuk berlindung dan merawat kawan-kawan dan masyarakat yang terluka. Korban kedua penembakan oleh aparat bernama Bernauds R Norma Irawan, mahasiswa Fakultas Ekonomi 
Atma Jaya, Jakarta. Ia tertembak di dadanya dari arah depan saat ingin menolong rekannya yang terluka di pelataran parkir kampus Atma Jaya, Jakarta. Mulai dari jam 15.00 WIB sampai dini hari, terus terjadi penembakan terhadap mahasiswa di kawasan Semanggi dan saat itu pula semakin banyak korban berjatuhan, baik yang meninggal tertembak maupun terluka. Gelombang mahasiswa dan masyarakat yang ingin bergabung terus berdatangan dan disambut dengan peluru dan gas air mata. Tragedi Semanggi 1 menyebabkan 18 orang meninggal karena ditembak aparat. Lima orang di antaranya adalah mahasiswa, yakni Teddy Mardani, Sigit Prasetya, Engkus Kusnadi, Herus Sudibyo, dan BR Norma Irmawan. Sedangkan korban luka-luka sebanyak 109 orang, baik masyarakat maupun pelajar.

Kasus pelanggaran HAM pada Tragedi Semanggi I telah ditindaklanjuti melalui jalur hukum yaitu dengan menghukum pelaku di lapangan. Namun belum mengena pada "otak pelaku” yang seharusnya paling bertanggung jawab pada tragedi tersebut. Sampai sekarang kasus-kasus pelanggaran HAM di Indonesia, belum ada satupun yang dapat diselesaikan melalui pengadilan. Hal ini disebabkan oleh banyak faktor, antara lain belum adanya pengadilan khusus yang berwenang memeriksa dan memutus perkara pelanggaran HAM yang berat. Hal inilah yang kadang menimbulkan gejolak dalam masyarakat dan hilangnya kepercayaan masyarakat terhadap pemerintah dan hukum di Indonesia (Walidain,2015: 3).

\section{PEMBAHASAN}

Kasus pelanggaran HAM memang selalu menjadi isu yang menarik. Bahkan semua yang melanggar kebebasan seseorang dinilai melanggar HAM. Kondisi ini mengingatkan pada mencuatnya isu kebebasan dan hak-hak dasar manusia yang pernah menjadi ikon kosmologi pada abad ke-18. Pada masa itu hak-hak dasar tidak hanya dipandang sebagai kewajiban yang harus dihormati penguasa. Tetapi, juga hak yang mutlak dimiliki oleh rakyat. Bahkan pada abad 18 muncul kredo ( pernyataan kepercayaan ) tiap manusia dikaruniakan hak-hak yang kekal. Hak yang tidak dapat dicabut dan yang tidak pernah ditinggalkan 
ketika umat manusia beralih untuk memasuki era baru dari kehidupan pramodern ke kehidupan modern. Serta tidak pernah berkurang karena tuntutan hak memerintah penguasa. Betapa HAM telah mendapatkan tempat khusus di tengahtengah perkembangan kehidupan manusia mulai abad 18 sampai sekarang.

Seorang penganut hukum alam Locke menyatakan bahwa masyarakat yang ideal adalah masyarakat yang tidak melanggar hak hak dasar manusia. Makna terdalam dari pernyataan Locke adalah untuk mencapai suatu tatanan kehidupan masyarakat diperlukan aturan ataupun perlengkapan yang dapat digunakan untuk menjaga eksistensi hak-hak dasar manusia. Perlengkapan yang diperlukan dalam upaya penegakan HAM adalah hukum. Seperti ungkapan dari Kant bahwa manusia sebagai makhluk berakal dan berkehendak bebas sehingga negara memiliki tugas untuk menegakkan hak-hak dan kebebasan warganya. Oleh karena itu penguasa dalam hal ini pemerintah tidak boleh melanggar maupun menghalangi. Kemakmuran dan kebahagiaan rakyat merupakan tujuan negara dan hukum.

Di Indonesia hukum seperti apa yang dalam pelaksanaannya dapat mewujudkan penegakan hak-hak manusia. Tentunya hukum yang benar-benar ditegakkan tanpa harus diwarnai dengan carut-marut ( segala coreng-moreng ) dunia politik. Bahkan dalam rangka melaksanakannya diperlukan orang-orang yang berani menentang arus atau mungkin orang yang telah putus syaraf takutnya menghadapi kedikdayaan penguasa. Demi kaum yang lemah.

Sepuluh tahun sudah tragedi Semanggi berlalu tanpa ada kepastian hukum. Saat ini kembali bangsa Indonesia memperingati momentum Mei berdarah, yang telah melahirkan pahlawan reformasi. Namun banyak orang yang sudah mulai lupa makna dibalik perjuangan para mahasiswa tersebut. Belum adanya titik terang tentang kasus Semanggi I sangat erat hubungannya dengan pernyataan Jaksa Agung Hendarman Supandji bahwa pihaknya kesulitan menangani kasus Semanggi I sebagai pelanggaran berat HAM. Tragedi Semanggi I yang dikategorikan termasuk Pelanggaran HAM berat, menjadi banyak tanda tanya di masyarakat. Oleh karena itu, Presiden Jokowi didesak untuk menerbitkan surat keputusan presiden untuk membentuk pengadilan HAM adhoc segera. 
Memerintahkan Jaksa Agung agar melakukan penyidikan kasus pelanggaran HAM berat Tragedi Semanggi I, 13 November 1998. Rekonsiliasi dengan pengungkapan Kebenaran (Judicial \& non judicial).

Akhirnya, pemerintah memutuskan untuk menyelesaikan kasus pelanggaran HAM berat tragedi Semanggi I melalui jalur non-yudisial atau rekonsiliasi. Ketua Komisi Nasional Hak Asasi Manusia ( Komnas HAM) Imdadun Rahmat mengatakan, keputusan tersebut diambil berdasarkan sikap politik pemerintah saat ini.

A. Penyebab Terjadinya Tragedi Semanggi

Perjuangan Order Reformasi dimulai dengan adanya krisis ekonomi yang melanda Indonesia tahun 1997. Dengan dipelopori mahasiswa, rakyat Indonesia mulai melawan ketidakadilan yang dilakukan Pemerintah Order Baru dan memperjuangkan demokratisasi di Indonesia. Pergantian pemerintahan dari Order Baru ke Order Reformasi memberikan harapan bahwa demokratisasi telah dimulai. Namun patut disayangkan bahwa krisis ekonomi sejak tahun 1997 belum membaik. Begitu juga permasalahan penegakan hukum, keadilan, dan kepastian hukum yang masih jauh dari yang diharapkan masyarakat. Akibatnya, terjadi beberapa kali kesalahpahaman atau bentrokan antara mahasiswa dan masyarakat dengan aparat pemerintah baik TNI maupun Polri serta terjadi peristiwa-peristiwa yang diduga merupakan pelanggaran hak asasi manusia. Kesalahpahaman dan bentrokan yang terjadi telah mengakibatkan jatuhnya korban dari pihak mahasiswa serta masyarakat maupun TNI atau Polri.

Pada bulan November 1998 pemerintahan transisi Indonesia mengadakan Sidang Istimewa untuk menentukan pemilu berikutnya dan membahas agendaagenda pemerintahan yang akan dilakukan. Mahasiswa bergolak kembali karena mereka tidak mengakui pemerintahan B.J Habibie dan tidak percaya dengan para anggota DPR/MPR Order Baru. Mereka juga mendesak untuk menyingkirkan militer dari politik serta pembersihan pemerintahan dari orang-orang Order Baru. Masyarakat dan mahasiswa menolak Sidang Istimewa 1998 dan juga menentang dwifungsi ABRI/TNI karena dwifungsi inilah salah satu penyebab bangsa ini tak pernah bisa maju sebagaimana mestinya. Benar memang ada kemajuan, tapi bisa 
lebih maju dari yang sudah berlalu, jadi boleh dikatakan kita diperlambat maju. Sepanjang diadakannya Sidang Istimewa itu masyarakat bergabunng dengan mahasiswa setiap hari melakukan demonstrasi ke jalan-jalan di Jakarta dan kotakota besar lainnya di Indonesia.

Peristiwa ini mendapat perhatian sangat besar dari dunia internasional terlebih lagi nasional. Hampir seluruh sekolah dan universitas di Jakarta, tempat diadakannya Sidang Istimewa tersebut, diliburkan untuk mencegah mahasiswa berkumpul. Apapun yang dilakukan oleh mahasiswa mendapat perhatian ekstra ketat dari pimpinan universitas masing-masing karena mereka di bawah tekanan aparat yang tidak menghendaki aksi mahasiswa. Sejarah membuktikan bahwa perjuangan mahasiswa tak bisa dibendung, mereka sangat berani dan jika perlu mereka rela mengorbankan nyawa mereka demi Indonesia baru.

B. Upaya Penyelesaian Dalam Pelanggaran

Pembentukan Komisi Penyelidikan Pelanggaran Hak Asasi Manusia Peristiwa Semanggi I dan Semanggi II Meskipun DPR RI telah merekomendasikan agar kasus Semanggi I dan II ditindak lanjuti dengan Pengadilan Umum dan Pengadilan Militer, namun sehubungan dengan adanya dugaan telah terjadinya pelanggaran HAM berat, tuntutan keadilan bagi keluarga korban dan masyarakat, dan dalam rangka penegakan hukum dan penghormatan hak asasi manusia, dipandang perlu Komnas HAM melakukan penyelidikan dengan membentuk Komisi Penyelidikan Pelanggaran HA Semanggi I, dan Semanggi II. Maka dalam Rapat Paripurna Komnas HAM tanggal 5 Juni 2001 menyepakati pembentukan Komisi Penyelidikan Pelanggaran Hak Asasi Manusia Peristiwa Semanggi I dan Semanggi II yang selanjutnya dituangkan dalam SK Nomor 034/KOMNAS HAM/VII/ 2001 tanggal 27 Agustus 2001.

\section{KESIMPULAN}

Penanganan dan penyelesaian tragedi Semanggi I tidak pernah mendapatkan kepastian hukum. Sepertinya keberadaan UU HAM, Komnas HAM, dan KPP HAM tidak berdaya mengungkap tragedi kemanusiaan tersebut. Ironisnya, justru memunculkan perbedaan pendapat. Apakah tragedi berdarah ini 
termasuk pelanggaran HAM berat atau bukan. Sebenarnya, ada apa dengan aparat penegak hukum kita.

Di Indonesia, hukum seperti apa yang dalam pelaksanaannya dapat mewujudkan penegakan hak-hak manusia. Tentunya hukum yang benar-benar ditegakkan tanpa harus diwarnai dengan carut manut dunia politik. Bahkan dalam rangka melaksanakannya diperlukan orang-orang yang berani menentang arus atau mungkin orang yang telah putus syaraf takutnya menghadapi kedikdayan penguasa demi kaum yang lemah. Semangat Negara hukum yang dianut Indonesia bukan hanya sekedar angan. Tetapi, merupakan pernyataan yang harus selalu menjadi acuan. Mengingat di dalamnya terkandung rasa hukum, kesadaran hukum dan aspek keadilan. Dalam pelaksanaannya penegakan HAM memang bukan hal yang mudah, meskipun sudah ada dasar konstitusional. Hal itu disebabkan masih adanya kendala yang terus menerus membayangi pelaksanaan HAM. Kendala pertama adalah kendala teknis - prosedural, yang menyangkut pembuktian secara hukum dan ketersediaan aturan hukum. Kedua, kendala politis yang ditandai oleh adanya kekuatan yang besar untuk menghambat upaya penyelesaian melalui pengadilan ( Moh. Mahfud MD, 2000 ).

Dalam penegakan HAM pergeseran konsep Negara hukum rawan terjadi. Terdapat pembenaran secara konstitusional berupa undang-undang atau peraturan perundang-undangan. Akibatnya, Negara hanya akan menjadi Negara undangundang.

Tragedi Semanggi I mungkin telah menjadi sejarah. Namun jangan sampai penegakkan hukum di Indonesia juga hanya menjadi cerita masa lalu. Jangan suatu tindakan pelanggaran terlepas dari kaca mata hukum hanya karena tertutup oleh isu-isu yang sedang hangat beredar atau adanya kepentingan tertentu. Aparat penegak hukum harus terus melebarkan sayapnya demi mewujudkan Indonesia sebagai Negara hukum. Itu tugas yang jelas diamanatkan pada mereka.

\section{DAFTAR PUSTAKA}

https://www.scribd.com/doc/21236942/Pelanggaran-HAM-dalam-tragedisemanggi 
https://nasional.kompas.com/read/2017/01/30/22270351/pemerintah.putuskan.pen yelesaian.kasus.trisakti.dan.semanggi.melalui.jalur.rekonsiliasi

https://brainly.co.id/tugas/3017695

https://isknews.com/pasal-1-angka-1-uu-no-39-tahun-1999-tentang-hak-asasimanusia-uu-ham/

http://hukum.unsrat.ac.id/uu/uu_39 99.htm

https://digilib.unila.ac.id/8594/3/BAB\%20II.pdf

https://nalarpolitik.com/latar-belakang-tragedi-semanggi-1/ 